Obere Extremität 2019 · 14:53-59

https://doi.org/10.1007/s11678-018-0485-x

Received: 11 May 2018

Accepted: 12 September 2018

Published online: 10 October 2018

(c) The Author(s) 2018

CrossMark

Monteggia-like lesions represent a rare but complex injury of the elbow joint [25] accounting for $2-5 \%$ of proximal forearm fractures [17]. The Italian surgeon Giovanni Battista Monteggia first described this lesion in 1814 as a fracture of the ulna shaft combined with an anterior dislocation of the radial head. However, the anterior dislocation of the radial head occurs in only about $25 \%$ of these complex elbow joint injuries.

Jose Luis Bado elaborated the pathomechanism and defined the term "Monteggia-like lesion" in 1957 as a complex injury to the elbow joint including a proximal ulna fracture and dislocation of the radial head $[1,2]$. However, additional lesions such as radiohumeral dislocation, ulnohumeral dislocation, proximal radioulnar dislocation, radial head fracture, and lesion of the distal radioulnar joint can occur [18].

Even for experienced surgeons, Monteggia-like lesions are a challenge. Accurate preoperative diagnostics are essential to determine the extent of the injury and plan further therapeutic steps. The detection of osseous injuries as well as of lesions affecting the capsule or ligaments is crucial. With surgical therapy, anatomic reduction of the joint should be strived for and instability should be addressed, in order to achieve normal joint function and allow early rehabilitation of range of motion (ROM).

There are only few publications on treatment of this injury. Probably due to the broad variety of Monteggia-like lesions, no treatment algorithm is currently available, and both treatment technique and results are variable. Therefore, the aim of this study was to retrospectively investigate our patients with Monteggialike lesions between 2014 and 2016, in

J. SchmalzI (D) - N. Sadler · M. Feucht · C. Gerhardt • L. J. Lehmann

Department of Traumatology and Hand Surgery, St. Vincentius Clinic, ViDia Clinics, Karlsruhe, Germany

\title{
Monteggia-like lesions
} A case series

order to analyze postoperative outcome and identify possible pitfalls.

\section{Methods}

Institutional review board approval was granted, and informed consent was obtained from each patient.

Searching our trauma database from January 2014 to December 2016, we identified 14 patients who were admitted and surgically treated due to a Monteggia-like lesion. We defined a Monteggia-like lesion as a proximal ulna fracture together with dislocation of the radial head and in combination with additional lesions such as radiohumeral dislocation, ulnohumeral dislocation, proximal radioulnar dislocation, and radial head fracture.

In all patients, preoperative CT scans of the injured elbow joint were obtained to rule out associated injuries and to improve preoperative classification and planning. According to the Bado classification, all 14 patients had a type II injury. Only 1 patient (7\%) presented with an open fracture, which was classified according to Gustilo and Anderson as a type I injury [11]. Bado type II lesions were subclassified according to Jupiter et al. [15]. There were four type IIa, one type IIb, four type IIc, and five type IId injuries. No associated nerve or vascular injuries were observed. Osteosynthesis of the ulna was performed with a variable angle locking compression plate (VA-LCP; Synthes, West Chester, PA, USA) in nine cases, with a double plate (Aptus, Medartis, Basel, Switzerland) in four cases, and with a tension plate (Aptus, Medartis, Basel, Switzerland) in one case. Use of the different plating systems depended on the surgeon's preference; the tension plate was used in case of a very proximal small single-fragment ulna fracture in a Bado/ Jupiter type IIa lesion. Although all radial head fractures were dislocation fractures per definition, we classified radial head fractures according to the Mason classification depending on the actual fragment dislocation in the preoperative imaging. These consisted of three Mason type II, four Mason type III, and seven Mason type IV fractures $[5,14,20]$. Depending on fracture pattern, fragment dislocation, and patient age, osteosynthesis, radial head replacement, or radial head resection was performed. Radial head fractures were either addressed "through the ulna" or by dissecting subcutaneously from the ulna to the posterolateral border and opening the radiocapitellar joint with the Boyd approach. A fractured coronoid process could be observed in nine cases. These fractures were classified according to O'Driscoll [21] and consisted of two O'Driscoll type 1 (one 1.1 and one 1.2), two O'Driscoll type 2 (two 2.2), and five O'Driscoll type 3 (five 3.2) lesions. In case of intraoperative ulnohumeral instability, these lesions were addressed either with indirect transosseous refixation according to the so called lasso technique described by Garrigues et al. [9], or with retrograde screw fixation through the olecranon plate. Intraoperative testing revealed 5 patients with lateral instability due to rupture of the lateral collateral ligament. In these patients, refixation of the lateral ligament complex was performed using suture anchors.

In all cases, surgical treatment was performed within the first $24 \mathrm{~h}$ after injury. Surgical therapy was provided by three different surgeons specialized in upper extremity and trauma surgery. Patients received standardized postoperative treatment with early immediate continuous active and passive motion. 
Table 1 Main characteristics of the 14 included patients and outcome parameters

\begin{tabular}{|c|c|c|}
\hline & Number & Percent \\
\hline Number of patients & 14 & 100 \\
\hline \multicolumn{3}{|l|}{ Gender } \\
\hline Male & 2 & 14 \\
\hline Female & 12 & 86 \\
\hline \multicolumn{3}{|l|}{ Injured side } \\
\hline Dominant arm & 8 & 57 \\
\hline Non-dominant arm & 6 & 43 \\
\hline \multicolumn{3}{|l|}{ Bado classification } \\
\hline Type I & 0 & 0 \\
\hline Type II & 14 & 100 \\
\hline Type III & 0 & 0 \\
\hline Type IV & 0 & 0 \\
\hline \multicolumn{3}{|l|}{ Bado/Jupiter classification } \\
\hline Type lla & 4 & 29 \\
\hline Type llb & 1 & 7 \\
\hline Type Ilc & 4 & 29 \\
\hline Type Ild & 5 & 36 \\
\hline \multicolumn{3}{|l|}{ Radius fracture } \\
\hline Radial head fracture Mason I & 0 & 0 \\
\hline Radial head fracture Mason II & 3 & 21 \\
\hline Radial head fracture Mason III & 4 & 29 \\
\hline Radial head fracture Mason IV & 7 & 50 \\
\hline \multicolumn{3}{|l|}{ Coronoid fracture } \\
\hline O’Driscoll Type 1 & 2 & 14 \\
\hline O'Driscoll Type 2 & 2 & 14 \\
\hline O'Driscoll Type 3 & 5 & 36 \\
\hline Lateral instability & 5 & 36 \\
\hline Open fracture & 1 & 7 \\
\hline Available for follow-up & 13 & 93 \\
\hline Mean age in years [range] & 63 [24-89] & - \\
\hline Mean follow-up in months [range] & $21.9[7-40]$ & - \\
\hline Mean ulnohumeral motion injured side in ${ }^{\circ}$ [range] & $116[70-155]$ & - \\
\hline Mean ulnohumeral motion contralateral side in ${ }^{\circ}$ [range] & $146[110-165]$ & - \\
\hline Mean forearm rotation inured side in ${ }^{\circ}[$ range] & $138[70-180]$ & - \\
\hline Mean forearm rotation contralateral side in ${ }^{\circ}$ [range] & $164[140-180]$ & - \\
\hline Mean Broberg and Morrey score [range] & $79[23-100]$ & - \\
\hline Mean Quick DASH score [range] & $23.6[0-61]$ & - \\
\hline Mean Mayo Elbow Performance Score [range] & $82[35-100]$ & - \\
\hline Mean subjective elbow value [range] & $66[20-90]$ & - \\
\hline Mean visual analogue scale [range] & $2.6[0-8]$ & - \\
\hline Cases requiring revision surgery other than implant removal & $3(23 \%)$ & - \\
\hline
\end{tabular}

Therefore, 2 to 5 days after surgery, an elbow orthosis for mobilization with an extension and flexion limitation of $0^{\circ}-30^{\circ}-120^{\circ}$ was adjusted and worn for 6 weeks after surgery [12]. addition, the distal radioulnar joint was examined for tenderness, and valgus and varus instability of the elbow joint were tested in full extension, if possible, as well as at $30^{\circ}$ of flexion. The overall functional outcome was assessed using the Broberg and Morrey Score (BMS) and the Mayo Elbow Performance Score (MEPS) as elbow-specific scores. Furthermore, the Disabilities of the Arm, Shoulder and Hand (DASH) questionnaire as well as the subjective elbow value (SEV) were used as patient-focused outcome tools. Additionally, a neurologic examination of the operated side was performed to detect sensory or motoric deficits. Postoperative radiographs of the elbow were routinely obtained 2 days after surgery. If medically indicated (pain/loss of function), additional radiographs of the elbow were performed during follow-up.

Due to the low case number, only a descriptive statistical analysis was performed using Excel (Microsoft, Redmond, WA, USA).

\section{Results}

A total of 13 patients were available for follow-up (93\%) at an average of 21.9 months (range 7-40 months) after surgery, while 1 patient had died of unrelated causes. Patients' main characteristics and the outcome parameters are reported in - Table 1 . In - Table 2, the individual results of each patient can be seen. According to the BMS [4], 2 (15\%) patients had excellent, 7 (54\%) good, 2 (15\%) fair, and 2 (15\%) poor results. Mean BMS was 79 (23 to 100), mean MEPS was 82 (35 to 100), mean DASH Score was 23.6 (0 to 61), and mean SEV was $66 \%$ (20 to 90 ). Average pain level on the VAS was 2.6 out of 10 points ( 0 to 8 ). Ulnohumeral ROM was $116^{\circ}$ (70 to $\left.155^{\circ}\right)$ on the injured side and $146^{\circ}(110$ to $160^{\circ}$ ) on the contralateral side. Mean forearm rotation was $138^{\circ}\left(70\right.$ to $\left.180^{\circ}\right)$ on the fractured side and $164^{\circ}\left(140-180^{\circ}\right)$ on the contralateral side. At followup, none of the patients demonstrated instability of the distal radioulnar joint or medial or lateral instability of the elbow.

In total, 3 patients underwent revision surgery other than implant removal 
Obere Extremität 2019 · 14:53-59 https://doi.org/10.1007/s11678-018-0485-x

(c) The Author(s) 2018

\section{J. Schmalzl · N. Sadler · M. Feucht · C. Gerhardt · L. J. Lehmann \\ Monteggia-like lesions. A case series}

Abstract

Introduction. Monteggia-like fractures are rare but complex injuries to the elbow joint, accounting for $2-5 \%$ of proximal forearm fractures. Even for experienced surgeons, their treatment can be challenging. The objective of this retrospective study was to analyze the short-term results after surgical treatment of Monteggia-like fractures in adults.

Methods. All patients who sustained a Monteggia-like fracture over a period of 3 years (2014-2016) and underwent surgical treatment in the authors' institution were followed-up. Pain level (visual analogue scale, VAS), range of motion (ROM), Broberg and Morrey Score (BMS), Mayo Elbow Performance Score (MEPS), Disabilities of the Arm, Shoulder and Hand (DASH) Score, and subjective elbow score (SEV) were recorded.

Results. Of 14 adult patients who sustained a Monteggia-like lesion during a 3-year period, 13 were available for follow-up after a mean time of 21.9 months (7 to 44 months). According to the BMS, 3 patients (15\%) showed excellent, 7 (54\%) good, 2 (15\%) fair, and $2(15 \%)$ poor results. A total of 3 patients (23\%) needed revision surgery other than implant removal. Mean BMS was 79 (23 to $100)$, mean MEPS was 82 (35 to 100), mean DASH score was 23.6 (0 to 61), mean SEV was $66 \%$ (20 to 90 ), and mean VAS was $2.6(0-8)$. Conclusion. Good short-term results can be achieved if the injury is classified correctly and a standardized surgical treatment of all injury components is performed. The results are comparable with data from the literature. Patients with Monteggia-like fractures should be informed about the risk of potential functional deficits and the possible need of further surgery.

Level of evidence. This study is evidence level IV.

\section{Keywords} Monteggia-like lesion - Radial head fracture . Coronoid fracture - Elbow luxation · Surgical treatment

\section{Monteggia-ähnliche Verletzungen. Eine Fallserie}

\section{Zusammenfassung}

Hintergrund. Monteggia-ähnliche Frakturen stellen seltene, aber komplexe Verletzungen des Ellbogengelenks dar, sie machen 2-5\% der proximalen Unterarmfrakturen aus. Selbst für erfahrene Chirurgen kann ihre Behandlung eine Herausforderung sein. Ziel der vorliegenden retrospektiven Studie war die Auswertung der Kurzzeitergebnisse nach chirurgischer Behandlung Monteggiaähnlicher Frakturen bei Erwachsenen. Methoden. Alle Patienten, die eine Monteggia-ähnliche Fraktur in einem Zeitraum von 3 Jahren (2014-2016) erlitten und bei denen in der Klinik der Autoren eine chirurgische Therapie erfolgte, wurden diesbezüglich nachbeobachtet. Schmerzniveau (visuelle Analogskala, VAS), Bewegungsumfang (,range of motion", ROM), Broberg-Morrey-Score (BMS), Mayo Elbow Performance Score (MEPS),
Disabilities of the Arm, Shoulder and Hand Score (DASH) sowie subjektiver EllbogenScore („subjective ellbow value", SEV) wurden dokumentiert.

Ergebnisse. Von 14 erwachsenen Patienten, die innerhalb eines 3-Jahres-Zeitraums eine Monteggia-ähnliche Fraktur erlitten, waren 13 für eine Nachuntersuchung nach im Mittel 21,9 Monaten (7-44 Monate) verfügbar. Gemäß BMS wiesen 3 Patienten (15\%) ausgezeichnete, 7 (54\%) gute, 2 (15\%) ausreichende und 2 (15\%) schlechte Ergebnisse auf. Insgesamt war bei 3 Patienten (23\%) eine Revisionsoperation, abgesehen von der Metallentfernung, erforderlich. Durchschnittlich betrug der BMS 79 (23-100), der MEPS 82 (35-100), der DASH-Score 23,6 (0-61), der SEV 66\% (20-90) und der Wert auf der VAS 2,6 (0-8).
Schlussfolgerung. Gute Kurzzeitergebnisse können erzielt werden, wenn die Verletzung korrekt klassifiziert und eine standardisierte chirurgische Behandlung aller Verletzungskomponenten durchgeführt wird. Die Ergebnisse sind den Daten aus der Literatur vergleichbar. Patienten mit Monteggiaähnlichen Frakturen sollten über das Risiko möglicher funktioneller Defizite und ggf. erforderliche weitere Operationen informiert werden.

Evidenzniveau. Diese Studie weist das Evidenzniveau IV auf.

\section{Schlüsselwörter}

Monteggia-ähnliche Fraktur · Radiuskopffraktur - Processus Coronoideusfraktur . Ellenbogen Luxation · Operative Therapie (overall revision rate $23 \%$ ). In one case, postoperative redislocation occurred due to persisting instability after failed transosseous coronoid refixation and primary radial head resection. Therefore, in the first revision, direct screw fixation of the coronoid process and implantation of a radial head prosthesis was performed; however, re-redislocation occurred. Because of extreme noncompliance and reduced general health, re-refixation of the coronoid process as well as a temporary transfixation of the elbow joint with an external fixator was realized in order to stabilize the joint. After removing the external fixator, joint stability was achieved; nevertheless, elbow function was severely limited. The prosthesis had to be removed after 1.5 years due to chronic subluxation causing severe elbow pain and a limited ROM. In another case, failure of radial head osteosynthesis was observed; thus, a secondary radial head prosthesis was implanted. In the third case, postoperatively persistent sensory irritation of the ulnar nerve occurred; consequently, revision surgery with neurolysis of the ulnar nerve was realized.

Implant removal was not counted as revision surgery. In total, 3 patients underwent elective implant removal-twice due to the young patient age (24 and 32 years) and in one case because of cosmetic demands.

Postoperatively, 3 patients (23\%) presented an associated neurological sensory deficit of the ulnar nerve. Two cases resolved without surgical intervention until 


\begin{tabular}{|c|c|c|c|c|c|c|c|c|c|c|}
\hline Patient & Bado/Jupiter & Mason & O'Driscoll & $\begin{array}{l}\text { Lateral } \\
\text { instability }\end{array}$ & $\begin{array}{l}\text { Revision } \\
\text { surgery }\end{array}$ & $\begin{array}{l}\text { Ulnohumeral } \\
\text { ROM }\end{array}$ & VAS & $\begin{array}{l}\text { Quick } \\
\text { DASH }\end{array}$ & MEPS & SEV \\
\hline 1 & $2 \mathrm{D}$ & 2 & - & - & - & 115 & 5 & 25 & 85 & 70 \\
\hline 2 & $2 A$ & 2 & 3.2 & Yes & Yes & 105 & 1 & 25 & 95 & 80 \\
\hline 3 & $2 \mathrm{~A}$ & 4 & 2.2 & - & - & 120 & 6 & 50 & 70 & 60 \\
\hline 4 & $2 A$ & 4 & 3.2 & Yes & Yes & 110 & 2 & 9 & 85 & 70 \\
\hline 5 & $2 \mathrm{D}$ & 4 & 3.2 & - & Yes & 70 & 8 & 61 & 35 & 20 \\
\hline 6 & $2 \mathrm{D}$ & 3 & 3.2 & Yes & - & 80 & 5 & 59 & 55 & 50 \\
\hline 7 & $2 \mathrm{~A}$ & 4 & 3.2 & Yes & - & 90 & 2 & 32 & 80 & 70 \\
\hline 8 & $2 B$ & 4 & 1.1 & - & - & 145 & 1 & 2 & 85 & 70 \\
\hline 9 & $2 C$ & 4 & - & - & - & 150 & 0 & 0 & 100 & 90 \\
\hline 10 & $2 \mathrm{D}$ & 3 & - & - & - & 120 & 0 & 5 & 100 & 80 \\
\hline 11 & $2 \mathrm{D}$ & 3 & 1.2 & - & - & 120 & 5 & 34 & 70 & 40 \\
\hline 12 & $2 C$ & 3 & - & - & - & 125 & 0 & 5 & 100 & 60 \\
\hline 13 & $2 C$ & 2 & - & - & - & 155 & 0 & 0 & 100 & 95 \\
\hline
\end{tabular}

follow-up; however, in one case, neurolysis of the ulnar nerve had to be performed.

No postoperative wound infection occurred in this case series.

\section{Discussion}

In our case series from January 2014 to December 2016, exclusively Monteggialike lesions Bado type II were registered. Several other authors also observed the predominance of Bado type II fractures in adults $[8,16,22,23,29]$, while in children and in cases of high-energy trauma, Bado type I injuries are more common $[28,32]$. Bado type I lesions show excellent or good functional outcomes in most cases, probably due to a low incidence of concomitant fractures of the radial head or the coronoid process [16, $28,32]$. In contrast, Bado type II lesions are reported to show significantly poorer outcomes [16, 26, 28]. Fractures of the radial head or the coronoid process have been reported to correlate with poor functional outcome scores and occur more frequently in older patients with associated bone weakness [16, 32]. Konrad et al. described Bado type IIa and IId lesions as negative prognostic factors [16]. In this context, our case series revealed similar results.

Our case series is too small to enable establishment of a data-based treatment algorithm. However, several pit- falls could be identified retrospectively, and the following treatment strategies can thus be recommended. In addition, two exemplary cases are illustrated in • Figs. 1 and 2.

First, in patients with concomitant radial head fractures, open reduction and internal fixation (ORIF) should be strived for, as patients undergoing radial head replacement showed worse clinical results in various studies examining the treatment of comminuted isolated radial head fractures $[3,27,31,33]$. In our experience, these findings can be transferred to Monteggia-like lesions. Minimally displaced radial head fractures (Mason type I/II) should be treated with screw fixation, plating represents a valid treatment option for radial neck fractures or comminuted fractures (Mason type III). Lindenhovius et al. reported that open reduction and internal fixation of unstable displaced fractures of the radial head occasionally fail, but could reduce the risk of subsequent elbow dislocation and protect against long-term arthrosis [19]. In severely comminuted and displaced fractures (Mason type IV) or in case of bad bone quality, ORIF becomes impossible and a radial head prosthesis should be implanted [27]. Ring et al. reported that ORIF of displaced fractures with more than three fragments is associated with early failure, nonunion, and loss of forearm rotation [27]. Therefore, a radial head prosthesis should be available when operating on a Monteggialike lesion with a comminuted radial head fracture. The literature shows that radial head excision is linked to inferior clinical results compared to ORIF and radial head prosthesis, as radiocapitellar contact is important for elbow and forearm stability [27]. Due to a subsequent loss of stability, radial head excision is contraindicated in acute situations and should only be considered as a salvage procedure or for elderly patients with low functional demands in order minimize operating time $[3,13,19,27]$. However, to date, this has only been examined for isolated radial head fractures and not in Monteggia-like lesions. As mentioned above, in our cohort, 1 patient underwent primary radial head resection due to severe intraoperative problems caused by morbid obesity. Postoperatively, this patient presented with persistent instability; however, it remains unclear whether this was caused by radial head resection or failed osteosynthesis of the coronoid fracture.

Second, olecranon fractures can be addressed with different techniques, as long as exact anatomical reposition and fixation is achieved. To date, it remains unclear whether any one of the available plating systems (VA-LCP vs. double plate vs. tension plate) is superior to the others; 

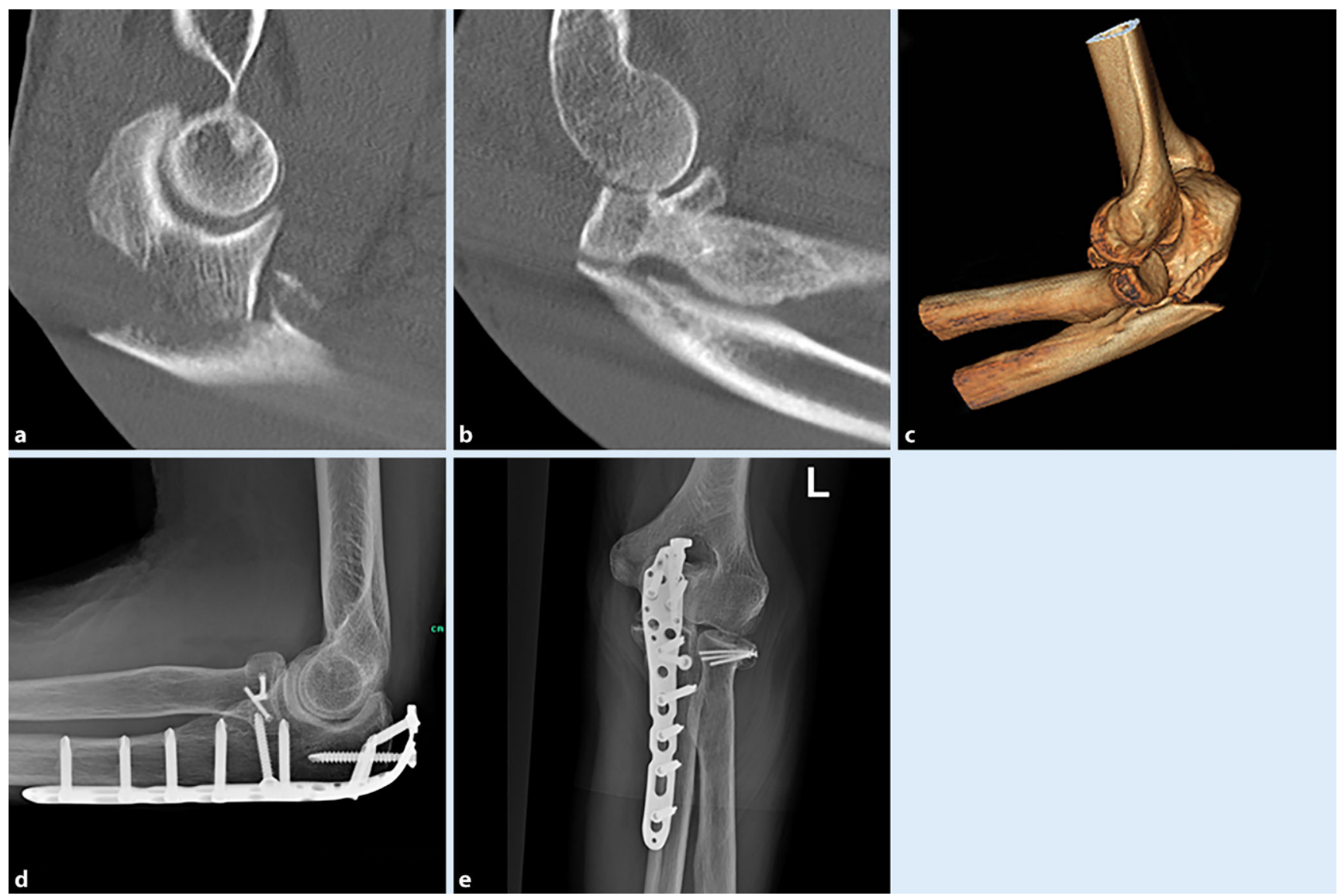

Fig. 1 A A6-year-old patient with a Monteggia-like lesion Bado/Jupiter type llb and a concomitant radial head fracture Mason type IV (preoperative images a-c). Open reduction and fixation of the ulna with a VA-LCP Olecranon (3.5/2.7 mm; Synthes, West Chester, PA, USA) and radial head osteosynthesis with three screws were performed. Postoperative images are shown in $\mathbf{d}$ and e. At 44 months follow-up, the patient had achieved good clinical results with 92 points in the Broberg and Morrey Score and 2 points in the Disabilities of the Arm, Shoulder and Hand Score. L left

thus, we recommend using the system the surgeon is most familiar with.

Third, fractures of the coronoid process can result in ulnohumeral instability $[7,24]$. For better evaluation of the coronoid fracture, the O'Driscoll classification should be used [21]. In this context, all O'Driscoll type 2 and 3 lesions must be addressed, as they potentially result in an unstable ulnohumeral joint. Special care should be taken in case of O'Driscoll type 2.3 lesions, which include fracture of the sublime tubercle, the ulnar insertion of the medial collateral ligament (MCL). Therefore, in an unstable posterior Monteggia-like lesion with fracture of the coronoid process, stable reduction of the coronoid fracture is necessary to restore ulnohumeral articulation, thereby providing elbow stability and minimizing the risk of future ulnohumeral arthritis due to chronic instabil- ity $[10,28]$. Depending on the fracture pattern, repair of the coronoid fracture can be realized either directly by ORIF with screws, volar plating, or suture anchors $[6,30]$, or with the lasso technique by passing a suture through the anterior capsular attachment, shuttling it through the ulna, and tying it down on the subcutaneous posterior border of the ulna $[9,30]$. Another possible technique is indirect osteosynthesis from the posterior ulna through the olecranon plate. In most O'Driscoll type I lesions the ulnohumeral joint remains stable and it is not necessary to address these fractures of the coronoid process; however, ulnohumeral joint stability has to be tested intraoperatively $[7,30]$.

Forth, our case series revealed that Monteggia-like lesions can be associated with concomitant lateral elbow instability. This has not yet been reported in the literature, although several case series of Monteggia-like lesions can be found [16, $18,32]$. In our study, four cases presented lateral elbow instability intraoperatively; therefore, refixation of the lateral ligament complex with suture anchors was performed. During the operation, lateral stability should be checked and in case of instability, refixation of the lateral capsule-ligament complex should be performed with a suture anchor.

Our study has strengths and weaknesses. Among the strengths is the relatively large population of adult patients having this uncommon injury with a very low loss to follow-up. Our study has the inherent limitations of a retrospective series. Moreover, the study cohort is quite inhomogeneous due to many influencing factors and the average follow-up of 21 months is rather short. 

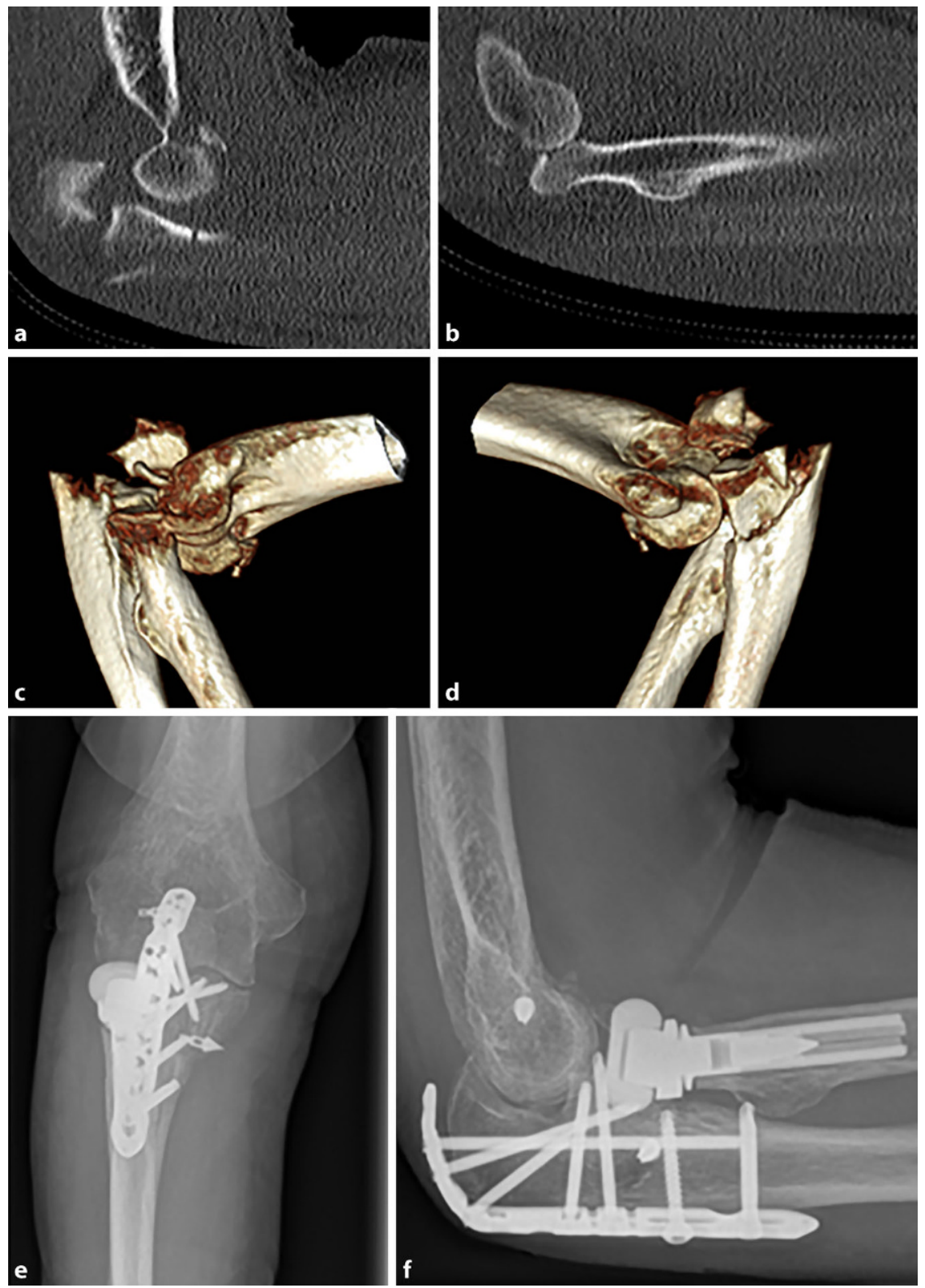

Fig. $2 \Delta$ A 75-year-old female with a Monteggia-like lesion Bado/Jupiter type lla and concomitant radial head fracture Mason type IV, coronoid fracture O'Driscoll type 3.2, and lateral instability (preoperative images a-d). Open reduction was performed with a VA-LCP Olecranon (3.5/2.7 mm; Synthes, West Chester, PA, USA), implantation of a radial head prosthesis (Mopyc; Wright Medical, Memphis, TN, USA), and refixation of the lateral collateral and the annular ligament with suture anchors. At 36 months follow-up, the patient had achieved good clinical results with 81 points in the Broberg and Morrey Score and 9 points in the Disabilities of the Arm, Shoulder and Hand Score

\section{Conclusion}

Our findings demonstrate that good short-term results can be achieved if the injury is classified correctly and a standardized surgical treatment of all injury components is performed. The results are comparable with the data in the literature. Patients with Monteggia-like fractures should be informed about the

\section{Corresponding address}

J.Schmalzl, MD
Department of Traumatology
and Hand Surgery, St.
Vincentius Clinic, ViDia Clinics
Suedendstraße 32,
76137 Karlsruhe, Germany
jonas.schmalzl@
vincentius-ka.de

\section{Compliance with ethical guidelines}

Conflict of interest. J. Schmalzl, N. Sadler, M. Feucht, C. Gerhardt, and L.J. Lehmann declare that they have no competing interests.

All procedures performed in studies involving human participants were in accordance with the ethical standards of the institutional and/or national research committee and with the 1964 Helsinki declaration and its later amendments or comparable ethical standards. The local ethics committee approved this study (Reg. Nr.: 2017-663 N-MA). Written consent was given by all participants.

Open Access. This article is distributed under the terms of the Creative Commons Attribution 4.0 International License (http://creativecommons.org/licenses/by/ 4.0/), which permits unrestricted use, distribution, and reproduction in any medium, provided you give appropriate credit to the original author(s) and the source, provide a link to the Creative Commons license, and indicate if changes were made.

\section{References}

1. Bado JL (1958) La lesion de Monteggia. InterMédica, Sarandi

2. Bado JL (1967) The Monteggia lesion. Clin Orthop Relat Res 50:71-86

3. Boulas HJ, Morrey BF (1998) Biomechanical evaluation of the elbow following radial head fracture: comparison of open reduction and internal fixation vs. excision, silastic replacement, and non-operative management. Ann Chir Main Memb Super 17(4):314-320. https://doi.org/10. 1016/S0753-9053(98)80031-8

4. Broberg MA, Morrey BF (1986) Results of delayed excision of the radial head after fracture. J Bone Joint Surg. https://doi.org/10.2106/00004623198668050-00005

5. Broberg MA, Morrey BF (1987) Results of treatment of fracture-dislocations of the elbow. Clin Orthop Relat Res. https://doi.org/10.1097/00003086198703000-00017

6. Clarke SE, Lee SY, Raphael JR (2008) Coronoid fixation using suture anchors. Hand 4(2):156-160. https://doi.org/10.1007/s11552-008-9142-ydoi: 10.1007/s11552-008-9142-y

7. Doornberg JN, Ring DC (2006) Fracture of the anteromedial facet of the coronoid process. J Bone Joint Surg. https://doi.org/10.2106/JBJS.E.01127

8. Egol KA, Tejwani NC, Bazzi J, Susarla A, Koval KJ (2005) Does a Monteggia variant lesion result in a poor functional outcome? A retrospective study. 
Clin Orthop Relat Res 438(438):233-238. https:// doi.org/10.1097/01.blo.0000168806.79845.8b

9. Garrigues GE (2011) Fixation of the coronoid process in elbow fracture-dislocations. JBone Joint Surg 93(20):1873. https://doi.org/10.2106/JBJS.I. 01673

10. Geßmann J, Königshausen $M$, von Glinski $A$, Rausch V, Schildhauer TA, Seybold D (2016) Das chronisch dezentrierte Ellenbogengelenk: Wieviel knöcherne Rekonstruktion, ligamentäre Rekonstruktion, wann Fixateur? Obere Extremität 11(4):218-227. https://doi.org/10.1007/s11678016-0379-8

11. Gustilo RB, Anderson JT (1976) Prevention of infection in the treatment of one thousand and twenty-five open fractures of long bones: retrospective and prospective analyses. J Bone Joint Surg Am 58(4):453-458

12. Hackl M, Leschinger $T$, Uschok $S$, Müller LP, Wegmann K (2017) Rehabilitation of elbow fractures and dislocations. Obere Extremität 12(4):201-207. https://doi.org/10.1007/s11678017-0425-1doi:10.1007/s11678-017-0425-1

13. Ikeda M, Sugiyama K, Kang C, Takagaki T, Oka Y (2005) Comminuted fractures of the radial head: comparison of resection and internal fixation. J Bone Joint Surg. https://doi.org/10.2106/jbjs.e. 00841

14. Johnston GW (1962) A follow-up of one hundred cases of fracture of the head of the radius with a review of the literature. Ulster Med J31:51-56

15. Jupiter JB, Leibovic SJ, Ribbans W, Wilk RM (1991) The posterior Monteggia lesion. J Orthop Trauma. https://doi.org/10.1097/00005131-19911200000003

16. Konrad GG, KundelK, Kreuz PC, Oberst M, Sudkamp NP (2007) Monteggia fractures in adults. J Bone Joint Surg Br 89-B(3):354-3360. https://doi.org/ 10.1302/0301-620X.89B3.18199

17. Korner J,Hoffmann A, Rudig L, MuellerL, Hessmann M, Lill H et al (2004) Monteggia-Verletzungen im Erwachsenenalter. Unfallchirurg. https://doi.org/ 10.1007/s00113-004-0825-8

18. Laun R, Wild M, Brosius L, Hakimi M (2015) Monteggia-like lesions - treatment strategies and one-year results. GMS Interdiscip Plast Reconstr Surg DGPW. https://doi.org/10.3205/iprs000072

19. Lindenhovius ALC, Felsch Q, Doornberg JN, Ring D (2007) Open reduction and internal fixation compared with excision for unstable displaced fractures of the radial head. J Hand Surg Am 32(5):630-636. https://doi.org/10.1016/j.jhsa. 2007.02 .016

20. Mason ML (1954) Some observations on fractures of the head of the radius with a review of one hundred cases. Br J Surg 42(172):123-132. https:// doi.org/10.1002/bjs.18004217203

21. O'Driscoll SW, Morrey BF, Korinek S, An KN (1992) Elbow subluxation and dislocation. A spectrum of instability. Clin Orthop Relat Res. https://doi.org/ 10.1097/00003086-199207000-00024

22. Pavel A, Pitman JM, Lance EM, Wade PA (1965) The posterior Monteggia fracture: a clinical study. J Trauma Acute Care Surg. https://doi.org/10. 1097/00005373-196503000-00006

23. Penrose JH (1951) The Monteggia fractue with posterior dislocation of the radial head. J Bone Joint Surg Br 33-B(1):65-73

24. Regan W, Morrey B (1989) Fractures of the coronoid process of the ulna. J Bone Joint Surg Am 71(9):1348-1354

25. Rehim SA, Maynard MA, Sebastin SJ, Chung KC (2014) Monteggia fracture dislocations: a historical review. J Hand Surg Am 39(7):1384-1394. https:// doi.org/10.1016/j.jhsa.2014.02.024doi:10.1016/j. jhsa.2014.02.024

26. Reynders P, De Groote W, Rondia J, Govaerts K, Stoffelen D, Broos PL (1996) Monteggia lesions in adults. A multicenter Bota study. Acta Orthop Belg 62(Suppl 1):78-83

27. Ring D (2008) Displaced, unstable fractures of the radial head: fixation vs. replacement-What is the evidence? Injury 39(12):1329-1337. https://doi. org/10.1016/j.injury.2008.04.011

28. Ring D, Waters PM (1996) Operative fixation of Monteggia fractures in children. J Bone Joint Surg $\mathrm{Br} 78-\mathrm{B}(5): 734-739$

29. Ring D, Jupiter JB, Simpson NS (1998) Monteggia fractures in adults. J Bone Joint Surg. https://doi org/10.2106/00004623-199812000-00003

30. Pugh DMW, Wild LM, Schemitsch EH et al (2004) Standard surgical protocol to treat elbow dislocations with radial head and coronoid fractures. JBone Joint Surg Am 86-A:1122-1130

31. Schmalzl J, Lehmann LJ (2017) Arthroscopically assisted osteosynthesis of radial head fractures. Obere Extremität. https://doi.org/10.1007/ s11678-017-0427-z

32. Suarez R, Barquet A, Fresco R (2016) Epidemiology and treatment of Monteggia lesion in adults: series of 44 cases. Acta Ortop Bras 24(1):48-51. https:// doi.org/10.1590/1413-785220162401152249

33. Wu PH, Shen L, Chee YH (2016) Screw fixation versus arthroplasty versus plate fixation for 3-part radial head fractures. J Orthop Surg (Hong Kong) 24(1):57-61. https://doi.org/10.1177/ 230949901602400114 